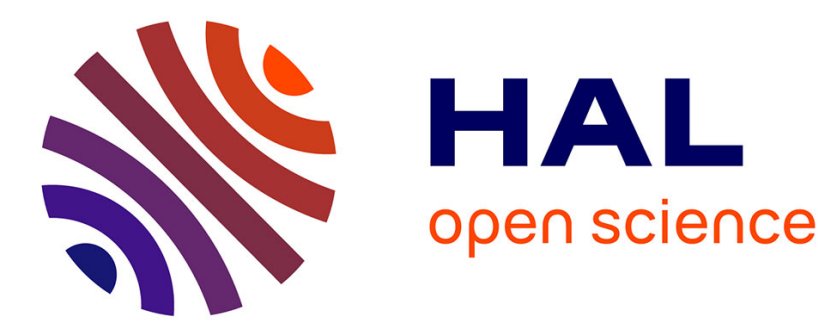

\title{
Small angle X-ray and neutron scattering from ganglioside micellar solutions
}

L. Cantù, M. Corti, Thomas Zemb, C. Williams

\section{To cite this version:}

L. Cantù, M. Corti, Thomas Zemb, C. Williams. Small angle X-ray and neutron scattering from ganglioside micellar solutions. Journal de Physique IV Proceedings, 1993, 03 (C8), pp.C8-221-C8-227. 10.1051/jp4:1993842 . jpa-00252273

\section{HAL Id: jpa-00252273 https://hal.science/jpa-00252273}

Submitted on 1 Jan 1993

HAL is a multi-disciplinary open access archive for the deposit and dissemination of scientific research documents, whether they are published or not. The documents may come from teaching and research institutions in France or abroad, or from public or private research centers.
L'archive ouverte pluridisciplinaire HAL, est destinée au dépôt et à la diffusion de documents scientifiques de niveau recherche, publiés ou non, émanant des établissements d'enseignement et de recherche français ou étrangers, des laboratoires publics ou privés. 


\title{
Small angle $X$-ray and neutron scattering from ganglioside micellar solutions
}

\author{
L. CANTÙ, M. CORTI ${ }^{*}$, T. ZEMB ${ }^{* *}$ and C. WILLIAMS ${ }^{* *}$
}

Department of Chemistry and Biochemistry, University of Milan, via Saldini 50, 20133 Milano, Italy

* Department of Electronics, University of Pavia, via Abbiategrasso 209, 27100 Pavia, Italy

${ }^{* *}$ C.E.A SCM, Bat. 125, C.E. Saclay, 91191 Gif-sur-Yvette cedex, France

${ }^{* * *}$ L.U.R.E., Bat. 109, Centre Universitaire Paris-Sud, 91405 Orsay cedex, France

\begin{abstract}
The ganglioside GM1 is a biological amphiphile with a double tail hydrophobic part and an oligosaccharide chain headgroup. In solution it forms micelles which interact by electrostatic repulsion. The micellar parameters obtained at low concentration by light and neutron scattering are used to interpret the small angle X-ray experiments performed at high concentration. The combination of the contrast inhomogeneity inside the micelle with the sharp structure-factor peaks, due to the strong electrostatic interaction, makes X-ray scattering spectra very sensitive to small changes in the micellar parameters.
\end{abstract}

\section{Introduction}

The ganglioside GM1 is an anionic surfactant of biological origin. It has an oligosaccharide chain made up of four neutral sugar groups plus a sialic acid residue as hydrophilic head, and a double chain hydrophobic part as phospholipids. The aggregation properties of various gangliosides have been investigated by static and dynamic light scattering in the last few years[1]. The ganglioside GM1 forms micelle in water with a very low critical micelle concentration $\left(\mathrm{cmc}\right.$ ), about $10^{-8} \mathrm{M}$. At a temperature of $25^{\circ} \mathrm{C}$, the micellar aggregation number is $\mathrm{N}=300$, with a molecular weight of 470000 Daltons. The ganglioside GM1, prepared as sodium salt, may hydrolyse in solution giving rise to charged micelles which interact electrostatically if the ionic strength of the solution is not so high as to screen the Coulomb repulsion completely[2,3].

We present in this paper a study of intermicellar interactions performed with light, neutron and X-ray scattering experiments in a large range of concentrations, from 0.004 to $0.3 \mathrm{~g} / \mathrm{cm}^{3}$. Data obtained with the three techniques can be consistently reproduced by modelling the radial distribution function $\mathrm{g}(\mathrm{r})$ of the particles in the hypernetted chain (HNC) approximation[4], using for the pair interaction potential a form consisting of a hard core repulsion plus a screened Coulomb potential. The X-ray spectra present an interesting double-peaked shape which is due to the combination of the structure factor with an oscillating micellar form factor. These spectra are quite sensitive to small changes in the solution parameters. 


\section{Laser light scattering experiments}

The effect of salt addition was studied at a fixed ganglioside concentration. Fig. 1 shows the behaviour of the scattered light intensity as a function of the ionic strength for a GM1 solution at a concentration of $0.0042 \mathrm{~g} / \mathrm{cm}^{3}$ and a scattering vector $\mathrm{k}=0.0023 \AA^{-1}$. The reported values are normalized by the intensity scattered from the ideal solution which was derived by measuring the scattered intensity at various GM1 concentrations in $30 \mathrm{mM} \mathrm{NaCl}$ solutions and extrapolated to zero micelle concentration. When $100 \mathrm{mM} \mathrm{NaCl}$ is added to the solution, the electrostatic charge of the micelle is well screened by the small ions, so that the solution behaves essentially as a system of noninteracting micelles. When no salt is added, the effect of electrostatic intermicellar interactions is so strong that the scattered light intensity is one order of magnitude lower than the value found in high ionic-strength conditions.

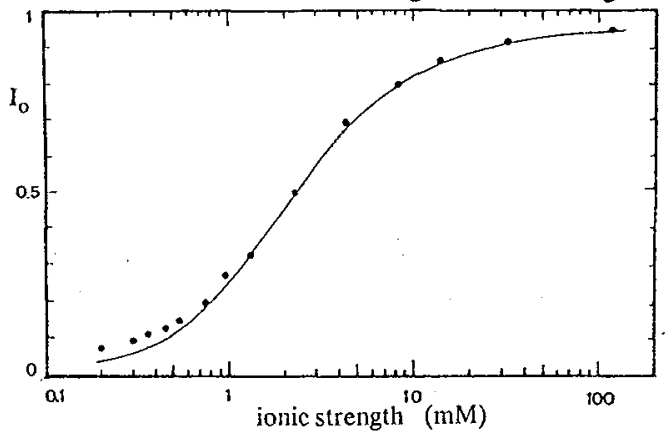

Fig.1. Normalized scattered light intensity versus ionic strength for a $0.0042 \mathrm{~g} / \mathrm{cm}^{3} \mathrm{GM} 1$ solution(dots). The full line is the theoretical result calculated for a micellar charge $Z=48$ electron units.

\section{Small angle neutron scattering}

Small angle neutron scattering experiments were performed at the D17 instrument of the Institute Laue-Langevin (Grenoble, France) at the same concentration as for the light scattering experiment, that is, $0.0042 \mathrm{~g} \mathrm{~cm}^{-3}$ in $\mathrm{D}_{2} \mathrm{O}$. Heavy water was used instead of normal water because of a better contrast.

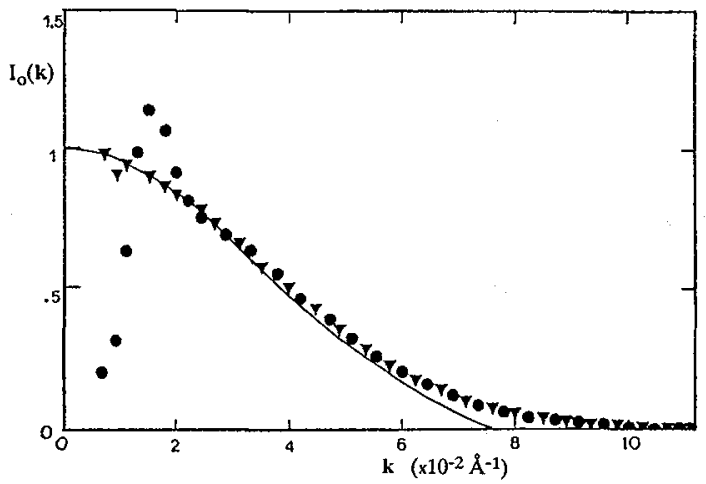

Fig.2. Intensity of scattered neutrons as a function of $\mathrm{k}$ for a $0.0042 \mathrm{~g} / \mathrm{cm}^{3} \mathrm{GM} 1$ ganglioside solution in pure $\mathrm{D}_{2} \mathrm{O}$ (dots) and with $100 \mathrm{mM} \mathrm{NaCl}$ (triangles).Intensities are rescaled with the value of the $\mathrm{NaCl}$ - solution intensity extrapolated to $k=0$. The full line is the micelle form factor,see text. 
Fig. 2 presents the neutron scattered intensity as a function of the $\mathrm{k}$ vector in pure $\mathrm{D}_{2} \mathrm{O}$ (dots) and in $100 \mathrm{mM} \mathrm{NaCl}$ (triangles). With no added salt, an interaction peak is evident, while for the $100 \mathrm{mM} \mathrm{NaCl}$ solution the intensity spectrum is just the form factor of the independent micelle since Coulomb interactions are completely screened. The fact that $I(k)$ does not depend on the ionic strength in the range $\mathrm{k}>3 \times 10^{-2} \AA^{-1}$ clearly indicates that the size and shape of the GM1 micelle are not influenced by the $\mathrm{NaCl}$ concentration. This extends and confirms previous light scattering results. Such a finding may at first seem surprising, since it is known for many ionic amphiphiles (for instance, the alkyl sulfates [5]) that the aggregation number depends considerably on the concentration of added salt. In the case of gangliosides, the headgroup is very bulky. As a consequence, the headgroup interactions are probably determined by steric rather than electrostatic contributions. This would explain the lack of sensitivity of $\mathrm{N}$ to the $\mathrm{NaCl}$ concentration.

\section{X-ray measurements}

X-ray small-angle scattering experiments were performed on the D22 double-crystal diffractometer in Lure (Orsay,France). Fig.3 shows the scattered intensity as a function of $\mathrm{k}$ for a $0.0042 \mathrm{~g} / \mathrm{cm}^{3}$ water solution of GM1 with $100 \mathrm{mM} \mathrm{NaCl}$. This is exactly the same measurement as the one reported in Fig.2 (full triangles) for small angle neutron scattering.

Both spectra represent the form factor of the same independent micelles. The difference between them comes from the internal inhomogeneity of the GM1 micelle which gives rise to different contrast profiles when probed with the two types of radiation. In the case of X-ray scattering, the hydrophobic part has a lower electron density than the solvent but the saccharidic part has a high electron density, larger than the solvent. The micelle is then seen as a hollow shell, giving rise to a pronounced second maximum in the measured form factor of Fig.3. This is not the case for neutron scattering, where the scattering length density of $\mathrm{D}_{2} \mathrm{O}$ is larger than both the hydrophobic and hydrophilic parts of the micelle. The crosses in Figs. $4 \mathrm{a}$, $4 \mathrm{~b}$ and $4 \mathrm{c}$ show the measured X-ray spectra at $25^{\circ} \mathrm{C}$ of the three GM1 water solutions at the concentrations of $0.15,0.25$ and $0.30 \mathrm{~g} / \mathrm{cm}^{3}$ respectively. The spectra present an interesting double-peak structure which is strongly concentration dependent.

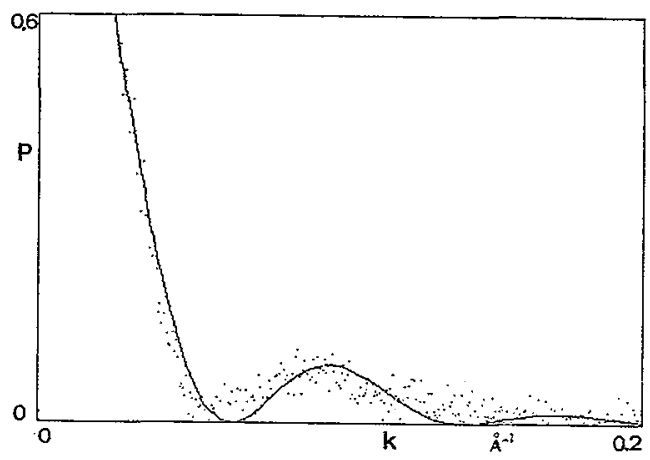

Fig.3. X-ray scattered intensity, normalized to 1 at $\mathrm{k}=0$, as a function of $\mathrm{k}$ for a $0.0042 \mathrm{~g} / \mathrm{cm}^{3} \mathrm{GM} 1$ ganglioside micellar-solution with $100 \mathrm{mM} \mathrm{NaCl}$. The full line is the micelle form factor, see text. 


\section{Interparticle interactions}

The intensity scattered by the micellar solution can be expressed as [6]

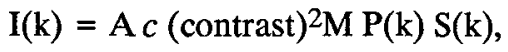

where $\mathrm{A}$ is an instrumental constant, $c$ is the amphiphile molar concentration, $\mathrm{M}$ the molecular weight, $\mathrm{P}(\mathrm{k})$ the micelle form factor and $\mathrm{S}(\mathrm{k})$ the structure factor which takes into account the effect of intermicellar interactions. Eq.(1) is valid under the following assumptions: $\mathrm{I}(\mathrm{k})$ should represent the excess scattering over the solvent scattering, $c$ is the total concentration minus the critical micelle concentration, the solution is monodisperse, and the particle orientation should be decoupled from interparticle interactions (this applies strictly to spherical particles).The structure factor is related to the radial distribution function $\mathrm{g}(\mathrm{r})$ as follows:

$\mathrm{S}(\mathrm{k})=1+4 \pi \mathrm{c}_{\mathrm{p}} \mathrm{k}^{-1} \int[\mathrm{g}(\mathrm{r})-1] \sin (\mathrm{kr}) \mathrm{dr}$

where $c_{p}=c N_{A} /\left(1000 N\right.$ ) is the micelle concentration (micelles $/ \mathrm{cm}^{3}$ ), and $\mathrm{N}_{\mathrm{A}}$ is the Avogadro number. The function $\mathrm{g}(\mathrm{r})$ can be calculated once the pair interaction potential $V(r)$ is known. Depending on the specific system under investigation, various approximations have been used to derive $\mathrm{g}(\mathrm{r})$ : the dilute gas approximation, the mean spherical approximation (MSA), the rescaled MSA and the hypernetted chain approximation(HNC)[4]. In the present case of a rather dense system with long range repulsive interactions, the $\mathrm{HNC}$ approximation seems quite adequate. The pair interaction potential consists of a hard-core repulsion plus the screened Coulomb potential

$\mathrm{V}(\mathrm{r})=(\mathrm{Ze})^{2} \exp [-\kappa(\mathrm{r}-2 \mathrm{a})] /\left[\varepsilon \mathrm{r}(1+\mathrm{ka})^{2}\right]$

where $\mathrm{a}$ is the micellar radius, $\mathrm{Z}$ is the charge in electron units, $\varepsilon$ the dielectric constant of water, $\mathrm{r}$ is the distance between the centers of the two micelles, and $\kappa$ is the inverse DebyeHuckel screening length expressed as[2]

$\kappa=\left[\left(2 \mathrm{e}^{2} / \varepsilon \mathrm{k}_{\mathrm{B}} \mathrm{T}\right)\left(0.5 \mathrm{Zc} / \mathrm{N}+\mathrm{c}_{\mathrm{S}}\right)\right]^{1 / 2}$,

where $c_{S}$ is the molarity of the added salt. Although GM1 micelles are known not to be exactly spherical[1], the form factor $\mathrm{P}(\mathrm{k})$ is calculated with a double shell spherical model. Whereas the core has a uniform scattering-amplitude (or electron) density, the hydrophilic layer presents a density which depends on the radius, going from the value typical of the saccharide groups at the inner surface to the value typical of water at the outer surface. Within a good approximation, the calculation can be simplified by assuming a mean uniform contrast of the outer shell as given by the hydrated sugars. 


\section{Discussion}

The continuous curve in Fig. 1 shows the structure factor $S(k)$, at $k=0.0023 \AA^{-1}$, calculated by means of eq.(2) and the HNC approximation for $\mathrm{g}(\mathrm{r})$, as a function of the ionic strength of the solution. The micellar charge is kept fixed, $Z=48$ and the ionic strength is calculated as $\mathrm{c}_{\mathrm{S}}+1 / 2 \mathrm{Zc} / \mathrm{N}$. The micellar radius and aggregation number, taken from light scattering data [1], are $\mathrm{a}=57 \AA$ and $\mathrm{N}=300$, respectively. The temperature is $25^{\circ} \mathrm{C}$.

The light-scattering parameters have also been used[3] to interpret the neutron scattering intensity at zero added salt, full dots in Fig.2. For this neutron experiment the micellar form factor has been assumed to be given by the scattered intensity measured at 100 $\mathrm{mM}$ added salt, triangles in Fig.2.

The same set of parameters are used again to reproduce the X-ray scattering data. The X-ray form factor, full line in Fig3, is calculated with a double-shell spherical micelle. In the GM1 molecule, the ceramide and the oligosaccharide chain have been considered the hydrophobic and the hydrophilic part, respectively. The resulting electron densities are 0.525 $\mathrm{e} / \mathrm{A}^{3}$ and $0.294 \mathrm{e} / \mathrm{A}^{3}$ for the saccharidic and lipid parts, taking $1.65 \mathrm{~g} / \mathrm{cm}^{3}$ and $0.877 \mathrm{~g} / \mathrm{cm}^{3}$ for the density values[1],respectively. The outer and inner radii are $57 \AA$ ad $43.5 \AA$. The outer layer thickness of $13.5 \AA$ is consistent with the length of the oligosaccharide chain[7]. With these data the average electron density of the outer layer, due to the presence of water, is $0.464 \mathrm{e} / \mathrm{A}^{3}$. The calculated form factor is in good agreement with the measured one, dots in Fig.3. The low concentration of GM1 and the added salt ensure the free particle behaviour of the micellar solution.

The same micellar model gives the neutron-scattering form factor, full line in Fig.2. The scattering-length densities are $-0.1 \times 10^{10} \mathrm{~cm}^{-2}$ and $4.37 \times 10^{10} \mathrm{~cm}^{-2}$,respectively, for the hydrophobic core and the hydrated sugar-shell.

The high concentration measurements are fitted with the X-ray form factor, discussed previously, and the structure factor $\mathrm{S}(\mathrm{k})$ calculated (in the HNC approximation) again with $\mathrm{Z}=48$ and $\mathrm{N}=300$. An example is shown in Fig.4. The ionic strength is just the one given by

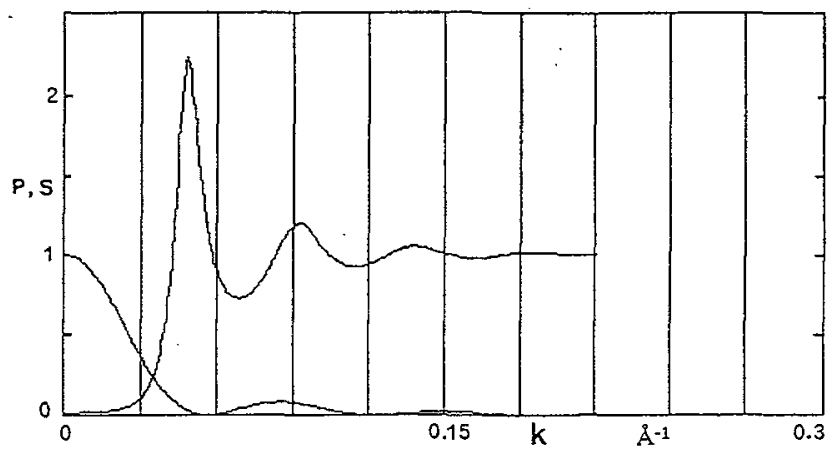

Fig.4. Calculated structure and form factors for the $0.30 \mathrm{~g} / \mathrm{cm}^{3} \mathrm{GM} 1$ micellar solution.

the micellar dissociation. The contribution of the free GM1 monomers in solution is neglected, since the cmc is so low. The full lines in Figs. 5a, 5b and 5c represent the calculated intensity, from eq.(1) and the crosses the experimental measurements. The general 

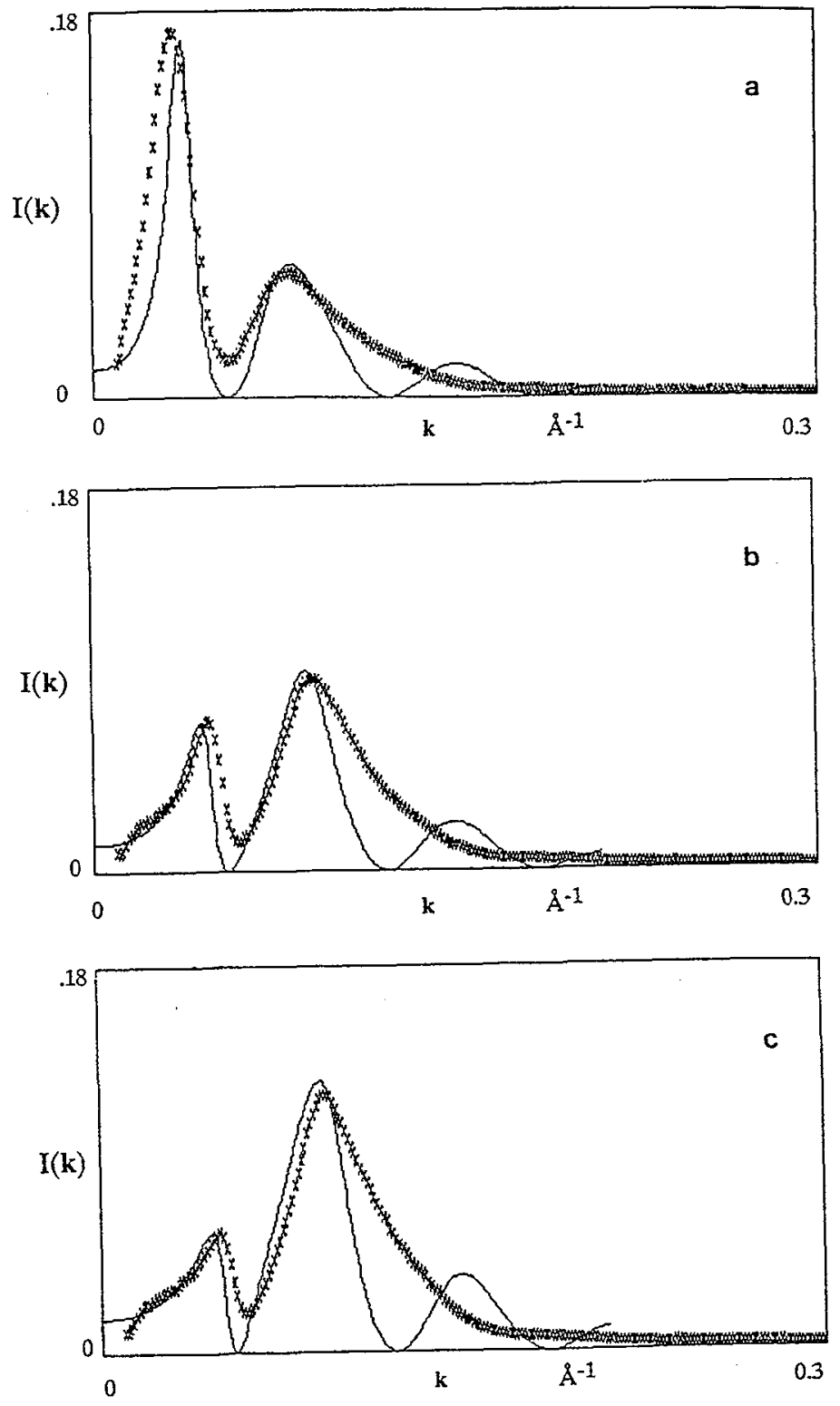

Fig.5. Scattered X-ray intensity (arbitrary units) as a function of $\mathrm{k}$ for three different concentrations: a) $0.15 \mathrm{~g} / \mathrm{cm}^{3}$, b) $0.25 \mathrm{~g} / \mathrm{cm}^{3}$ and c) $0.30 \mathrm{~g} / \mathrm{cm}^{3}$. Full lines are the calculated spectra, all with the same micelle form-factor. 
quality of the fit is excellent considering that there is no adjiustment of the parameters, despite the simple spherical approximation of the micelle shape.

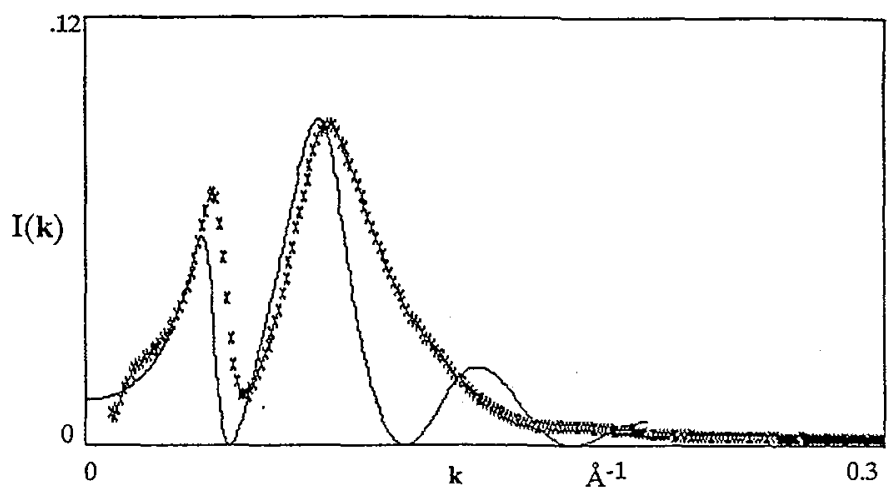

Fig.6. Change in the quality of the fit of the data of Fig. $5 \mathrm{~b}$ when the external radius of the micelle is taken to be $58.5 \AA$ instead of $57 \AA$.

Finally, it is important to notice that the interplay of a sharp structure factor with the doublepeaked X-ray form factor, makes the intensity spectra very sensitive to small changes of the micellar parameters. As an example, Fig. 6 shows the change in the quality of the fit when the external radius of the micelle is changed by only $1.5 \AA$.

\section{Acknowledgements}

Authors are very grateful to L.Belloni for kindly giving us the computer program used to calculate $\mathrm{S}(\mathrm{k})$. Work partially supported by Consiglio Nazionale delle Ricerche Progetto Finalizzato Chimica Fine II.

\section{References}

[1] Corti M.,Cantù L., and Salina P., Advances in Colloid and Interface Sci.,36 (1991) 153.

[2] Cantù L.,Corti M. and Degiorgio V., Faraday Discuss. Chem.Soc.,83 (1987) 287.

[3] Cantu L.,Corti M.,Degiorgio V.,Piazza R.,and Rennie A.,Prog. Colloid Polym.Sci. 76 (1988) 216.

[4] Belloni L.,in Neutron,X-Ray and Light Scattering, P.Lindner and T.Zemb eds.(Elsevier Science Publishers B.V.) 1991.

[5]Minero C.,Pramauro E.,Pellizzetti E.,Degiorgio V. and Corti M, J. Phys. Chem. 90 (1986) 1620

[6] Pusey P.N. and Tough R.J., in Dynamic Light Scattering.Applications of Photon Correlation Spectroscopy,R.Pecora ed.,(Plenum Press, New York) 1985.

[7] Maggio B., $B B A 815$ (1985) 245. 